\title{
16 Developing a Consultative Bayesian Model for Integrated Management of Aquatic Resources: an Inland Coastal Zone Case Study
}

\author{
E. Baran, ${ }^{1}$ T. Jantunen ${ }^{2}$ and P. Chheng ${ }^{3}$ \\ ${ }^{1}$ WorldFish Center, Phnom Penh, Cambodia, e-mail: e.baran@cgiar.org \\ ${ }^{2}$ Environmental Consultant, Phnom Penh, Cambodia \\ ${ }^{3}$ Inland Fisheries Research and Development Institute, Phnom Penh, Cambodia
}

\begin{abstract}
This chapter presents the methodological aspects of the development of a decision support system (DSS) based on Bayesian networks and aiming at assisting in the management of water-dependent resources (rice, fish, shrimp and crab). The principles of Bayesian networks are introduced, then the steps of model development are detailed and illustrated by the BayFish model being developed in the inland coastal zone of Bac Lieu Province (Vietnam). The particular feature of this DSS is that it is based on the contribution of local stakeholders. The process of building the model is detailed and illustrated by examples, in particular: the modalities of stakeholder consultations, the progressive arrangement of variables into a structured network, the justifications and weights defining each of the variables, the integration of databases in the model so that it combines quantitative and qualitative information, and the way outputs are calculated. The model, once completed, allows planners and decision-makers to visualize the trade-offs among various water management options. It also highlights the socio-political options and choices inherent to environmental management.
\end{abstract}

\section{Introduction}

Coastal zones are areas subject to high population pressure. In 1995, over 39\% of the world's population lived within $100 \mathrm{~km}$ of a coast, whereas the coastal area accounts for only $20 \%$ of all land area (Burke et al., 2000). The conflicts that result from this pressure are considerable, and technical as well as policy tools are needed to propose optimized land-use options and solutions to these conflicts.

On the technical side, in response to this need, decision support systems (DSS) have been developed in recent years to handle a large number of variables, their interactions and feedback loops. They have also been developed to integrate information originating from multiple disciplines, and to assess the outcomes of a given decision, which is almost always beyond the reach of individual experts. However, the specificity of land and water management is that it has implications for the livelihoods of millions of persons, and thus goes far beyond engineering and includes societal and political choices (Ostrom, 1990). In that regard, the contribution of civil society - either at the grass-roots 
level or through representatives - is to be considered as an intrinsic component of the management process and of the decision support tools (Kasemir et al., 2000; Gregory et al., 2001).

Among the various types of computerbased decision support tools, Bayesian networks are relatively unique in their ability to integrate quantitative information and data as well as qualitative expert knowledge and subjective choices (Varis and FrabouletJussila, 2000; Cain 2001; Lynam et al., 2002).

In this chapter, we introduce the principles of Bayesian networks applied to environmental management and to the role and modalities of stakeholder consultation, and use the ongoing development of a Bayesian support system in Bac Lieu Province (Vietnam) as an example of consultative integrated management of aquatic resources in inland coastal zones.

In Bac Lieu Province, saline water intrusion inland is partially controlled by sluice gates that create an artificial freshwater environment, which favours rice farming but is detrimental to brackish-water aquaculture and fish production. This leads to conflicts among various users whose water-quality requirements vary significantly (Hoanh et al., 2003).

The model being developed to assist in water management in this province is named BayFish-Bac Lieu, following two similar models named BayFish-Mekong, focusing on Mekong fish production (Baran et al., 2003), and BayFish-Tonle Sap, developed for Tonle Sap fisheries in Cambodia (Baran et al., 2004). The model is intended mainly for the use of planners and decision-makers at the provincial level. The objectives of BayFish-Bac Lieu are:

- to help in optimizing the operations of the sluice gates in terms of fish production;

- to assist, through the production of scenarios, in making informed decisions about water management options;

- to identify and inform all stakeholders about the trade-offs inherent to water management options and production outputs; and

- to involve stakeholders in the management process.
In the following sections, we present an overview of the Bayesian approach, followed by the steps that have been achieved so far:

- a consultation with stakeholders for the identification of critical variables and zones,

- the creation of a conceptual framework that summarizes these interactions and

- the parameterization of the model with stakeholders and experts.

Two final steps will be achieved in 2005-2006 through the comprehensive integration of databases and results from other surveys and studies, and the production of scenarios and sensitivity analyses. Thus, this chapter focuses on the methodological aspects of the modelling approach.

\section{Principles of Bayesian Networks}

Bayesian networks consist of defining the system studied as a network of variables linked by probabilistic interactions (Jensen, 1996). Bayesian networks are also called Bayes' nets or Bayesian belief networks (BBN). These methods based on the calculation of dependent probabilities (Bayes' theorem) were originally developed in the mid-1990s as decision support systems (DSS) for medical diagnosis. Their principles and application to environmental management have been detailed in Charniak (1991), Ellison (1996), Cain (2001) and Reckhow (2002).

Variables representing the modelled environment can be either quantitative (e.g. 'number of fishers') or qualitative (e.g. 'fishing strategy'). For each variable, a small number of classes is specified. One of the challenges when building any kind of model is in defining enough, but not too many, variables. Probabilities based on the best available knowledge - either data-based or qualitative - quantify the link between two connected variables. Figure 16.1 shows an example.

In a driven variable, or child node, all the possible combinations of driving variables, or parent nodes, are integrated (see Fig. 16.2). 


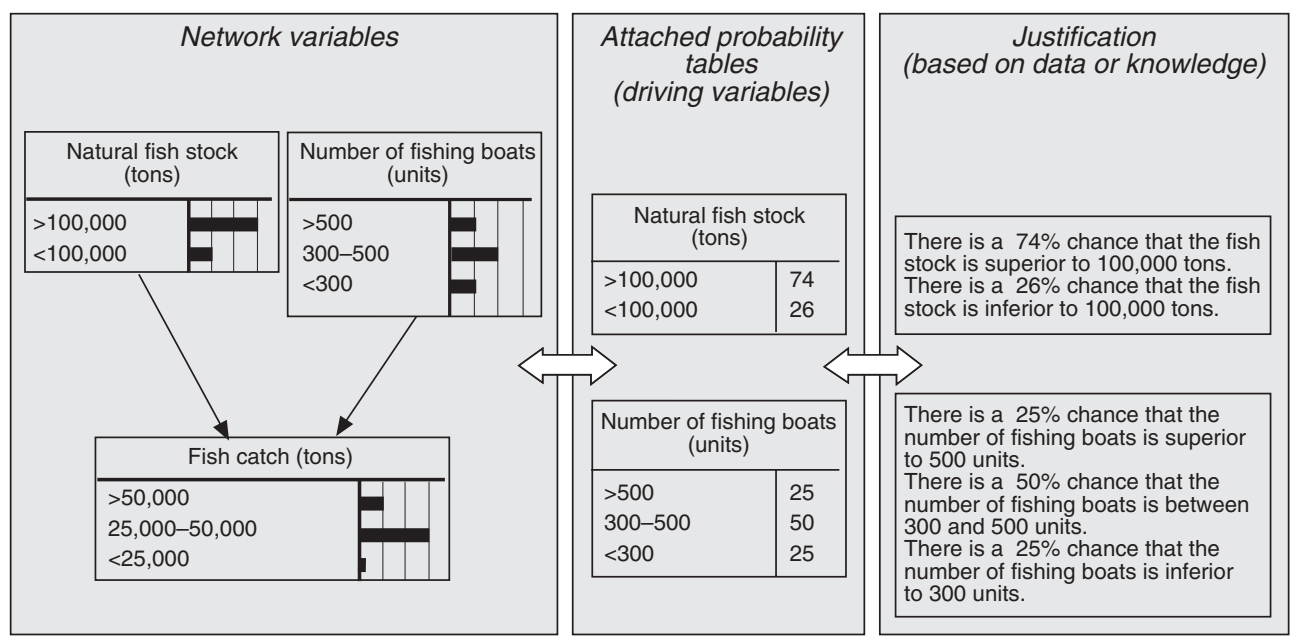

Fig. 16.1. Mini-network of three connected variables representing a hypothetical fishery (left). The probabilities of the first two driving variables are detailed in the middle section and the justification is detailed in the right section.

\begin{tabular}{|c|c|c|c|c|c|c|c|}
\hline \multicolumn{5}{|c|}{$\begin{array}{l}\text { Driving variables and probability } \\
\text { table of the driven variables }\end{array}$} & \multirow{3}{*}{$\begin{array}{c}\text { Justification } \\
\text { (detailed example for } \\
\text { one combination) }\end{array}$} & \multirow{2}{*}{\multicolumn{2}{|c|}{$\begin{array}{c}\text { Computer calculation (based } \\
\text { on Bayes formula) of the } \\
\text { probability of having a certair } \\
\text { catch given all the previous } \\
\text { probabilities }\end{array}$}} \\
\hline \multicolumn{2}{|c|}{$\begin{array}{l}\text { Natural fish stock } \\
\text { (tons) }\end{array}$} & \multicolumn{3}{|c|}{$\begin{array}{c}\text { Number of fishing boats } \\
\text { (units) }\end{array}$} & & & \\
\hline $\begin{array}{l}>100,000 \\
<100,000\end{array}$ & $\theta$ & \multicolumn{2}{|c|}{$\begin{array}{l}>500 \\
300-500 \\
<300\end{array}$} & 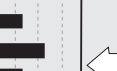 & & & \\
\hline \multirow{2}{*}{$\begin{array}{l}\text { Stock } \\
\text { (tons) }\end{array}$} & & & & & \multirow{8}{*}{\begin{tabular}{|l|} 
If the stock is $>100,000$ \\
tons \\
If there are $300-500$ boats \\
- there is a $60 \%$ chance \\
that the catch is superior \\
to 50,000 tons \\
- there is a $30 \%$ chance \\
that the catch is between \\
25,000 and 50,000 tons \\
- there is a $10 \%$ chance \\
that the catch is inferior \\
to 25,000 tons
\end{tabular}} & & \\
\hline & $\begin{array}{l}\text { Boats } \\
\text { (units) }\end{array}$ & \multicolumn{3}{|c|}{ Catch (tons) } & & & \\
\hline$>100,000$ & $>500$ & 0 & 1 & & & \multirow{2}{*}{\multicolumn{2}{|c|}{ Fish catch (tons) }} \\
\hline 2100.000 & $300-500$ & 60 & $\frac{10}{30}$ & $\frac{0}{10}$ & & & \\
\hline$>100,000$ & $<300$ & 20 & 20 & 60 & & $>50,000$ & 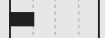 \\
\hline$<100,000$ & $>500$ & 10 & 70 & 20 & & $25,000-50,000$ & \\
\hline$<100,000$ & $300-500$ & 10 & 30 & 60 & & $<25,000$ & 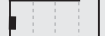 \\
\hline$<100,000$ & $<300$ & 0 & 10 & 90 & & & \\
\hline
\end{tabular}

Fig. 16.2. Mini-network of three connected variables representing a hypothetical fishery (continued). The probability table of the driven variable is detailed in the middle section and the resulting probabilistic computation is given in the right section.

Thus, the sequence of tasks in model development is as follows:

- Building the model framework: (i) to identify the major variables of the system studied; and (ii) to arrange them into a meaningful network.

- Specifying the classes of each variable to specify a few relevant states for each variable.
- Parameterizing variables: (i) to define the probability of each state of each driving variable (a process called 'elicitation of prior probabilities'); and (ii) to define for each driven variable the probabilities of each combination of driving variables.

If data are available, the quantified relationship between two variables is automatically converted into probabilities. If data are 
not available, expert knowledge (an expert being any person having first-hand experience of the system studied) can be applied to express the known relationship between two variables in terms of probabilities. Ultimately, the software calculates, based on the Bayes formula of combined probabilities, the probability of having a certain output given the state of all the driving variables.

The possible integration of expert knowledge into a modelling framework contributed significantly to the success of the Bayesian approach, which is nowadays being more and more broadly used (e.g. McKendrick et al., 2000; Hahn et al., 2002; Soncini-Sessa et al., 2002; Bertorelle et al., 2004).

Different software is available to build and run Bayesian networks (review in Arthington et al., 2004), although some modelling teams prefer to develop their own (e.g. Varis, 2003). For the development of this BayFish-Bac Lieu model, Netica software (<http://www.norsys.com>) was chosen. This package is intuitive and user-friendly, does not require the mastering of a computer language and is easily accessible on the Internet, where a freeware version allows the development of small models and the running of any large model.

\section{Building a Consultative Model: Steps and Examples}

\section{The consultative process}

In using Bayesian networks for environmental management, consultation with experts and stakeholders is acknowledged as being of critical importance (Borsuk et al., 2001; Ravnborg and Westermann, 2002; Cain et al., 2003). This consultation has been described with more or fewer details in almost all studies using Bayesian networks. However, for modelling applications dealing with societal issues such as natural resource management, studies focusing on the consultation process and its methodology are scarce (Reckhow, 2002). Some authors have addressed specific aspects of consultation, in particular the theoretical side (Gregory et al., 2001; Beierle, 2002; Wilkins et al., 2002; Seidel et al., 2003), whereas others have highlighted the psychological pitfalls inherent in consultation with individuals or stakeholders (Anderson, 1998; De Bruin et al., 2002; Fenton, 2004). On the more practical side, the guidelines provided by Cain (2001) and Ravnborg and Westermann (2002) for stakeholder consultations are among the most detailed. Acknowledging the lack of concise and pragmatic recommendations, Baran and Jantunen (2004) have proposed guidelines about stakeholder consultation for Bayesian modelling, detailing in particular possible options about the selection and number of stakeholders, group consultation options and pitfalls, and issues specific to Bayesian networks.

\section{Example: the consultation for the BayFish-Bac Lieu model}

Stakeholders were identified as follows: fishers, farmers and aquaculturists (for first-hand experience at the district level); technicians and extension officers in these disciplines (for the field experience at the provincial level); representatives of local organizations and of line agencies (for institutional roots); provincial representatives (for the administrative and political viewpoint); academe (for the research follow-up); and, in theory, equal proportions of men and women, even if achieving this balance proves impossible because of both professional and cultural reasons.

The stakeholders were informed in advance about the purposes of the exercise: (i) to identify the relevant environmental variables that drive aquatic food production in the area studied; (ii) to build a model framework that will reflect what users say about the interactions among these variables; and (iii) to give a weight to each variable and to the role it plays in food production or in the factors that drive food production.

Consultations were conducted on the following basis:

- Identification of the stakeholders matching the above criteria by the provincial authorities. Although other ways of identifying stakeholders do exist (Baran and Jantunen, 2004), this was the only possible 
one given the time frame and the centralized administrative structure in Vietnam.

- Ten to 15 participants per meeting; women were represented as well, but were a silent minority.

- A first round of half-day consultations at the commune level, to assess the contemporary state and constraints in different agro-ecological zones (mainly rice farming, aquaculture and brackish-water zone). Each zone was discussed separately. The consultations involved: (i) a facilitator familiar with the modelling approach to solicit contributions from the stakeholders and lead the debate; (ii) the modellers asking specific questions on variables and linkages, and checking the logic of the system; and (iii) a translator with field experience for the modellers to follow the debate in Vietnamese, who would not intervene too much and would be competent to cross-check the answers. The consultations were followed by conversion of the information gathered into a computer model by the modellers and the facilitator (another half day).

- A second round of consultations with the same stakeholders to verify model structure and variables identified during the first round.

- Additional discussions involving highlevel technicians or scientists (e.g. agronomists from the Department of Agriculture and Rural Development, hydrodynamics modellers from the International Water Management Institute, etc.) and provincial managers (in particular, representatives of the Bac Lieu People's Committee) in order to: (i) check that variables and linkages significant at the provincial scale were not missing from the model developed at the district level; (ii) test the acceptability by provincial authorities of the model proposed; and (iii) identify the availability of data and statistics supplementing expert knowledge wherever possible.

\section{Building the model framework}

A preliminary model framework, introducing progressively the environmental vari- ables and their links in the system modelled, is to be presented to stakeholders so that they can understand the approach and expectations. Then, stakeholders are requested to build from scratch a model of their own, starting with the main variables of interest, whose components and driving factors are progressively detailed.

\section{Building the BayFish-Bac Lieu basic framework}

Three half-day consultations were held in three different communes (one in the freshwater zone, one in the brackish-water zone and one in the saline zone outside the sluice gates) during the first round. Important variables were identified, which showed that total aquatic food production in the province is composed of shrimp, rice, fish and crab. The production of each commodity depended, to various degrees, on water supply and water quality. The three models developed in the three areas were then integrated into a single one by the modellers. This model was subsequently checked, modified and agreed upon during a second round of consultations, another half day for all the same stakeholders. The basic framework obtained is detailed in Fig. 16.3.

Each level was further detailed until a

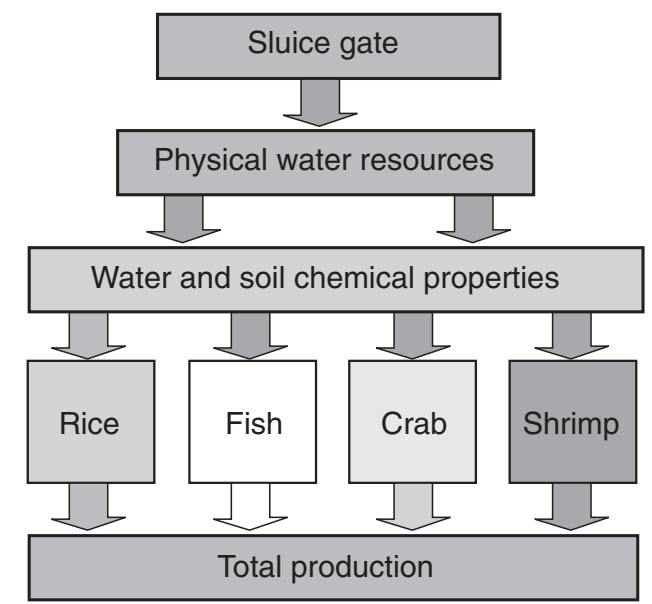

Fig. 16.3. Bac Lieu water and food model, overall structure flow diagram. 
final framework was agreed upon by all stakeholders at the end of the consultations (Fig. 16.4).

\section{Building the BayFish-Bac Lieu detailed framework}

To show how variables are defined, links set and contributions weighted, we detail below an excerpt of the BayFish model, specifically the module detailing fish production variables (see Fig. 16.4). All probabilities assigned resulted from stakeholder consultations and averaging was used between different consultations only when stakeholders failed to agree upon one value.

F1. Fish production is the combination of wild fish and aquaculture fish production. Wild fish are caught in canals and aquaculture fish are cultivated with shrimp and crabs in ponds or in rice paddies. Overall, $30 \%$ of the fish produced are estimated to originate from aquaculture and 70\% from wild fish capture. Fish production is season-specific, that is, fish grow more during the wet season, but at the moment this growth is not quantified in the model.

F1.1. Wild fish production depends on the combination of estuarine fish and freshwater fish production. Estuarine fish refer to marine fish that migrate to the province from the sea, whereas freshwater fish refer to fish living and migrating within the province and from the Mekong River. Estuarine fish are estimated to contribute $80 \%$ of the production and wild freshwater fish $20 \%$.

F1.1.1. Estuarine fish production depends on water quality for estuarine wild fish and marine inflow. Stakeholders value the importance of local water quality vis-à-vis estuarine fish production at $70 \%$, and that of marine inflow through the sluice gates at 30\% (because a proportion of the marine fish comes from the Gulf of Thailand, outside the area controlled by sluice gates built along the South China Sea coastline).

F1.1.1.1. Water quality for estuarine wild fish depends on organic water pollution and chemical water pollution. Chemical pollution causes biological problems and organic pollution causes, among others, anoxia problems and fish kills. Stakeholders estimate that $70 \%$ of the problems are due to organic pollution (mainly from shrimp-processing factories), whereas $30 \%$ of the pollution problems relate to chemicals (mostly pesticides from rice farming).

F1.1.2. Freshwater fish production depends on water quality for freshwater wild fish and upstream inflow. Upstream inflow refers to fish larvae and food supply, originating mainly from the Mekong River. The weight given to water quality is $70 \%$ and that given to upstream inflow is $30 \%$.

F1.1.2.1. Water quality for freshwater wild fish depends on organic water pollution, chemical water pollution and water salinity. Pollution problems have been detailed above and salinity is not acceptable to fish of freshwater origin. Subsequently, the weight given to salinity is $50 \%$, whereas organic pollution and chemical pollution receive $35 \%$ and $15 \%$, respectively.

F1.2. Aquaculture fish production results from the semi-intensive aquaculture method, extensive aquaculture method, soil acidity and water quality for aquaculture fish. Examples of species produced are Oxyeleotris marmorata (marble goby) and Barbonymus gonionotus (Java barb). Stakeholders consulted estimate that water quality contributes $40 \%$ to aquaculture fish production. Out of the $60 \%$ remaining, averaging between proportions given in different district consultations shows that $87.5 \%$ (i.e. $52.5 \%$ overall) is due to the aquaculture mode and $12.5 \%$ (i.e. $7.5 \%$ overall) to soil acidity. Extensive aquaculture farms make up $90 \%$ of the cases and semiintensive ones $10 \%$.

F1.2.1. The semi-intensive fish aquaculture method depends on stocking of fish seeds, application of fish feed as well as suitable water quantity for fish. Feed and seeds play an equal role, $80 \%$ overall, whereas the role of water supply is valued at $20 \%$.

F1.2.1.1. Fish seeds are the basis for fish cultivation and only natural seeds are used. Some $40 \%$ of the farmers use few seeds (generally $3 / \mathrm{m}^{2}$ ) and $60 \%$ of the farmers use a lot of seeds (around $10 / \mathrm{m}^{2}$ ).

F1.2.1.2. Fish feed is usually caught locally from channels. Some $30 \%$ of the farmers use 'little' feed (i.e. around 10 tons/ha/year), 


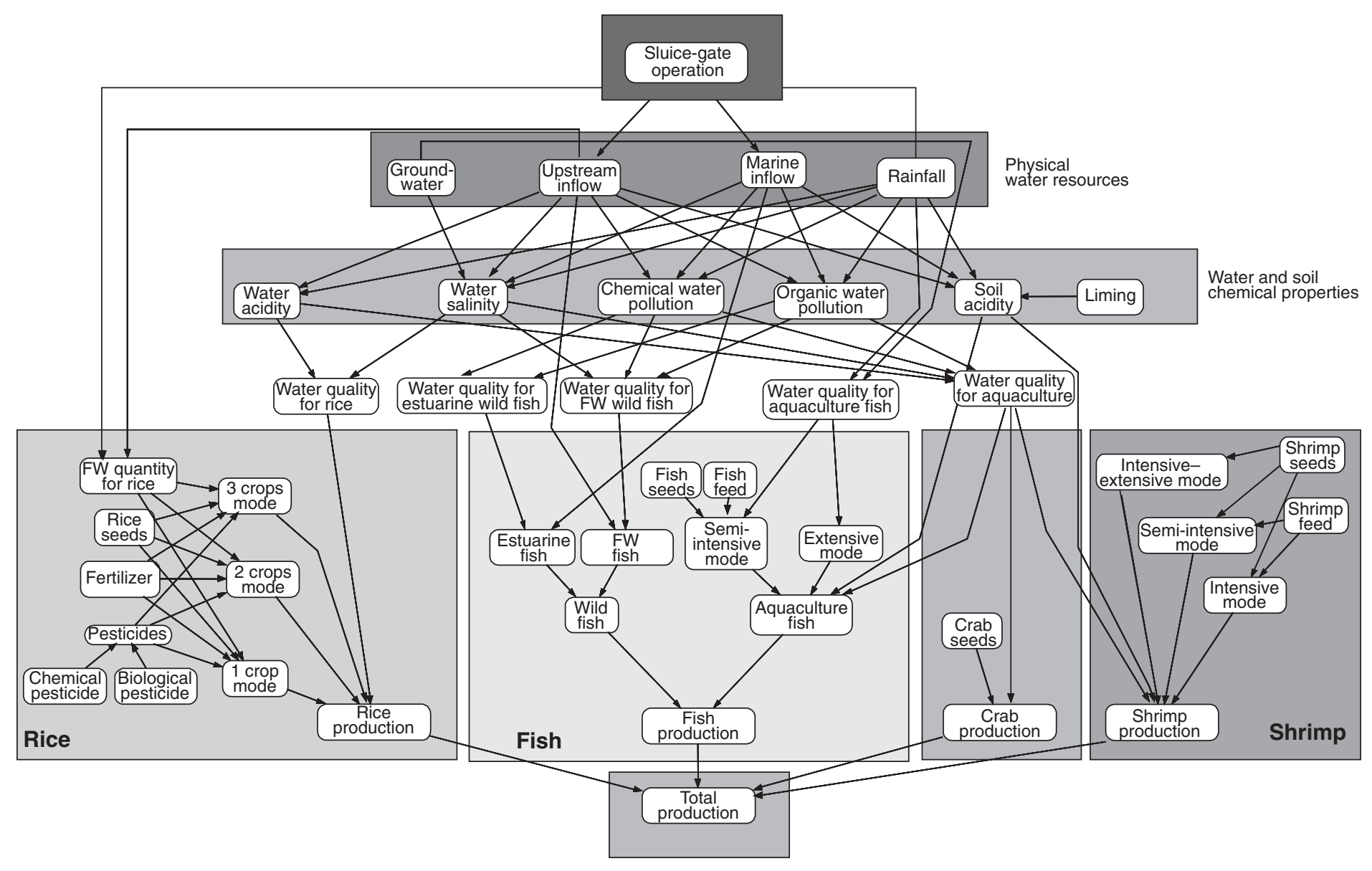

Fig. 16.4. Network of variables in the BayFish-Bac Lieu water-dependent food production model. FW, fresh water. 
whereas $70 \%$ of them use 'a lot' of feed (about 14 tons/ha/year).

F1.2.1.3. Water quantity for fish results from groundwater and rainfall. Both groundwater and rainfall provide necessary unpolluted fresh water in situ for the ponds. The role of groundwater is dominant (weight estimated at $80 \%$ by stakeholders), while that of rainfall is only $20 \%$.

F1.2.2. The extensive fish aquaculture method depends only on water supply (water quantity for fish). This latter result shows that, according to stakeholders, sluice-gate operations do not influence freshwater fish aquaculture (only groundwater and rainfall do).

\section{Specifying the variable classes}

The variables of a Bayesian model have to be defined and specified according to a number of states, such as 'Yes' or 'No', 'High' or 'Low', ' $x<5$ ', ' $5 \leq x \leq 7$ ' or ' $x>7$ ', etc. Cain (2001) details the constraints of this operation; in particular, states have to be discrete (i.e. discontinuous) and limited in number in order to avoid overly complex and unmanageable probability tables. We provide below two examples of variable specification drawn from the BayFish-Bac Lieu model: variables pesticides (qualitative specification) and rainfall (fully quantitative specification).

Example 1: specifying the variable 'Pesticides' in the Rice module of the BayFish-Bac Lieu model

- Biological pesticides as well as chemical pesticides are used in the area. Biological pesticides such as DTN 32 and DTN 16 are of plant origin and are less toxic than chemical pesticides; however, they are also less efficient against pests. They are nevertheless preferred by some farmers, who can then grow shrimp or fish in the same location after the annual rice harvest.

Chemical pesticides such as deltamethrin are very efficient and secure for rice production, but have a strong negative effect on the survival of shrimp and fish juveniles.
- For biological pesticides, a small dose is considered to be around $0.25 \mathrm{l} / \mathrm{ha}$, according to farmers and extension officers, whereas a large dose consists of at least $0.5 \mathrm{l} / \mathrm{ha}$.

- For chemical pesticides, a small dose is considered to be around $0.5 \mathrm{l} / \mathrm{ha}$, according to farmers and extension officers, whereas a large dose consists of at least $1 \mathrm{l} / \mathrm{ha}$. Most of the farmers who prefer large doses are in the rice-farming area and cannot grow shrimp anyway. One must note that those latter farmers used to spray about $31 /$ ha a few years ago, thus the notion of 'a lot' has evolved over time.

- Having detailed in the parent nodes what products and doses were, the integrative child node pesticides is simply specified in terms of 'a little' or 'a lot' of pesticides (Fig. 16.5), depending on the combination amount of chemical and biological pesticides.

Example 2: specifying the variable 'Rainfall' in the Physical Water Resources module of the model

The rainfall variable is based on both long and short time-series data sets from the Provincial Departments of Meteorology and Hydrology: 1910-1990 (eight stations with gaps, from 1930 to 1950 and the mid-1970s) and 2002-2003 (three stations, no gaps). Frequency distribution graphs show that the rainy season occurs from July to November, with an average annual rainfall (in those 5 months) of $1325 \mathrm{~mm}$. The dry season (from December to June) exhibits an average annual rainfall of $580 \mathrm{~mm}$ in those 7 months and the frequency distribution of dry-season rainfall data is nearly normal. The authors decided to use, as in the Vietnam River System and Plains (VRSAP) model (Hoanh, 1996), the dry-season months as an input in the model, with a threshold value of $580 \mathrm{~mm}$ to qualify either rainy or dry years. Distribution analysis shows that, in available data, years with more than average dry-season rainfall constitute $55.6 \%$ of the cases, whereas years with less than average dry-season rainfall constitute $44.4 \%$ of the cases (Fig. 16.6). 


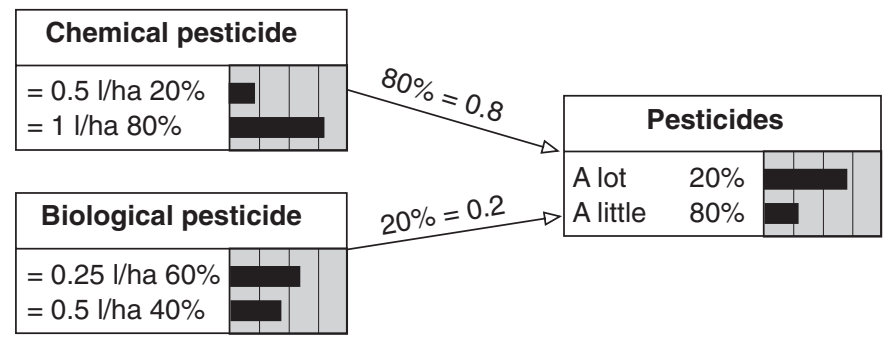

Fig. 16.5. Specification of the variable 'Pesticides' in the Rice module of the model.

\begin{tabular}{|l|l|l|l|}
\hline \multicolumn{2}{|c|}{ Rainfall } \\
\hline Above $580 \mathrm{~mm} \quad 55.6 \%$ & & \\
Below $580 \mathrm{~mm} \quad 44.4 \%$ & & & \\
\hline
\end{tabular}

Fig. 16.6. Specification of the variable 'Rainfall' in the Physical Water Resources module of the model.

\section{Parameterizing the model variables}

Parameterizing the variables of the model consists of attributing a probabilistic value to each possible combination of parent variables ('probability elicitation'). This is also to be done by stakeholders once all the variables of the framework have been identified and specified. An efficient way of eliciting probabilities is to ask stakeholders to give a weight to each variable, then to fill in all possible combinations of the weighted variables combined. We detail this process in two examples: pesticides in the Rice module and total production resulting from rice, fish, shrimp and crab production.

\section{Example 1: parameterizing the variable} 'Pesticides' in the Rice module of the model

- Around $40 \%$ of the farmers prefer to use small doses of biological pesticides to minimize the impact on fish or shrimp, whereas $60 \%$ of them use large doses.

- Around $20 \%$ of the farmers who use chemical pesticides prefer to use small doses, and $80 \%$ of them use large doses.

- Overall, $80 \%$ of the farmers use chemical pesticides and $20 \%$ use biological pesticides.

These statistics are illustrated in Fig. 16.7.
The software simply calculates resulting probabilities according to the Bayes formula, which can be expressed as

Probability $P$ of event A knowing conditional event

$$
\begin{aligned}
& \mathrm{E}=P(\mathrm{~A} \mid \mathrm{E})=[P(\mathrm{E} \mid \mathrm{A}) \\
& \times P(\mathrm{~A})] / P(\mathrm{E})
\end{aligned}
$$

Example 2: parameterizing the variable 'Total production' of the BayFish-Bac Lieu model

Total production is usually understood in terms of tons of a commodity, but for most farmers consulted production means contribution to income. In the model developed, the contribution of each commodity to production is subsequently expressed in terms of contribution to income, and the estimates provided in different locations were simply averaged (as only one set of values could be input in the current model; Table 16.1).

Beyond the technicality of averaging or weighting answers lies a much more crucial question, that of units and thus viewpoints. In Bac Lieu Province, for instance, the 'contribution to total production' is dominantly perceived in terms of tons (e.g. contribution of the province to national rice production) and in terms of income (e.g. motivation for farmers to grow shrimp rather than rice when $1 \mathrm{~kg}$ of shrimp is worth about $50 \mathrm{~kg}$ of rice). In the BayFish-Bac Lieu model, we followed the dominant stakeholders' perception and expressed the share of each commodity in financial terms (Vietnamese dong or US dollars). However, other viewpoints might be preferred, such as food security (each commodity then being expressed in tons) or land use (number of hectares 


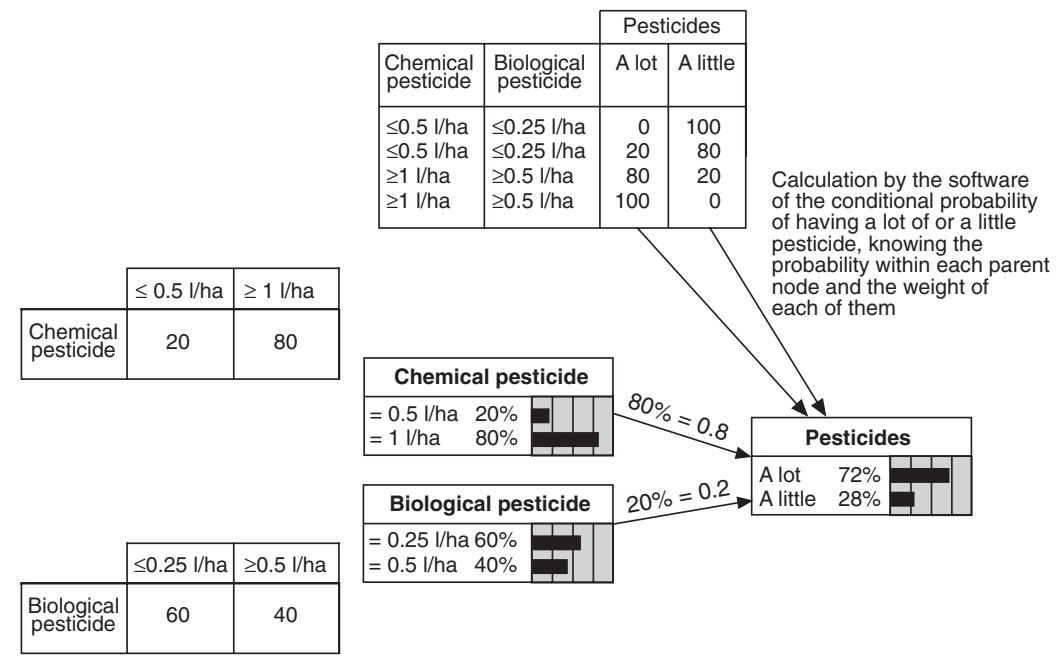

Fig. 16.7. Probabilities attached to pesticides and the resulting calculation of conditional probabilities.

needed to produce a given commodity), as detailed in the second part of Table 16.1.

It is to be noted that the management of sluice gates is to be done in response to a desired output, such as maximized income or maximum food security. The latter belongs to the socio-political realm, and the technical role of a decision support tool consists of identifying optimal ways to achieve an objective once this objective is clearly identified.

\section{Conclusions}

Bayesian networks have been developed in recent years in the fields of natural resource management (review in Cain, 2001), fisheries management (Varis and Kuikka, 1997; Kuikka et al., 1999; Marcot et al., 2001) and watershed management (Borsuk et al., 2001; Varis, 2003). However, only a few of these models have been based on extensive stakeholder consultations.

In the field of environmental management, the strength of models based on Bayesian networks and stakeholder consultations is that they give stakeholders and managers a chance to visualize trade-offs between conflicting uses and needs, thus contributing to conflict resolution and management optimization. The consultationbased approach also permits us to overcome

Table 16.1. Contribution of each commodity to Production, and meaning of 'Production'. In italics, the values kept in the model.

\begin{tabular}{lccccl}
\hline & \multicolumn{4}{c}{$\begin{array}{c}\text { Contribution (\%) of each } \\
\text { commodity to 'Total production' }\end{array}$} & \\
\cline { 2 - 5 } Location & Rice & Fish & Crab & Shrimp & Production understood as \\
\hline Phong Thanh & 20 & 5 & 5 & 70 & Income \\
Phong Thanh Tay & 5 & 15 & 15 & 65 & Income \\
Ho Phong & 10 & 15 & 15 & 60 & Income \\
Vinh Loi & 20 & 5 & 5 & 70 & Income \\
Mean of 4 locations & 13.8 & 10 & 10 & 66.3 & Income \\
Vinh Loi & 50 & 10 & 0 & 40 & Area of land necessary year-round \\
Ho Phong & 0 & 5 & 15 & 80 & Area of land necessary in dry season \\
Ho Phong & 10 & 15 & 15 & 60 & Area of land necessary in wet season \\
Vinh Loi & 90 & 5 & 2.5 & 2.5 & Food security \\
\hline
\end{tabular}


the lack of data in certain fields, and results in integration of both quantitative data and qualitative information based on experience. However, it remains possible to replace qualitative, consultation-based information by data when the latter become available (Fig. 16.8).

The BayFish-Bac Lieu model is based on extensive stakeholder consultations, but it also integrates existing environmental databases (in particular, rainfall records from the Provincial Departments of Meteorology and Hydrology, and outputs of the VRSAP hydrodynamic model; Hoanh et al., 2001). The Bayesian structure allows the prediction (in qualitative terms so far, i.e. a percentage between 'good' or 'bad') of changes in water management (in particular, through sluicegate operations) for each of the four main food commodities.

Although not dynamic, the BayFish model includes spatial as well as temporal dimensions (e.g. quality of estuarine versus freshwater; effect of liming on soil acidity, etc.). It is not detailed by geographic area but integrates the specificities and requirements of the main shrimp and rice production zones.

The model is intuitive and user-friendly, as clearly confirmed by the straightforward contribution of farmers and fishers. Running and modifying it require computer conversance, but no knowledge of any specific programming language. Netica, the software required to run it, is freely available on the Internet. Lastly, sources are open (i.e. the model structure and contents are fully modifiable) and of very small size (a few hundred kilobytes).
A sensitivity analysis (not detailed here) allows for the identification of the variables that contribute most to the overall variability of the system modelled; this analysis, based on entropy calculation (Coupé et al., 1999, 2000), classifies variables according to their degree of influence on the output of interest.

The model produced, although still under development, already provides a picture of the different and conflicting water quality requirements of rice, shrimp, crab and fish that all contribute to the economy and food supply of Bac Lieu Province. There is currently a conflict between the governmentrun policy of expanding rice culture area, which requires fresh water, and lucrative shrimp farming, which requires brackish water. Pushing further the questioning initiated during the stakeholder consultations, a policy targeting economic return would drive sluice-gate operations favourable to shrimp culture, whereas a policy targeting food security for the poor would command sluice-gate operations favourable to fish and rice, and one favouring biodiversity conservation would place weight on fish and crab natural production.

A model like BayFish allows the quantification of trade-offs and the production of scenario analyses, but its technical requirements also highlight the need for a clear identification of the socio-political options that drive environmental management. Thus, consultative modelling can efficiently assist in the management of inland coastal zones provided that the question 'What for?' is addressed and tentatively answered.

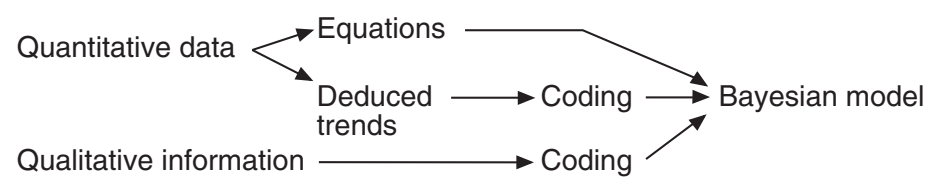

Fig. 16.8. Possible inputs for a Bayesian network. 


\section{References}

Anderson, J. (1998) Embracing uncertainty: the interface of Bayesian statistics and cognitive psychology. Conservation Ecology. <http:// www.consecol.org/vol2/iss1/art2>

Arthington, A.H., Baran, E., Brown, C.A., Dugan, P., Halls, A.S., King, J.M., Minte-Vera, C.V., Tharme, R.E. and Welcomme, R.L. (2004) Water Requirements of Floodplain Rivers and Fisheries: Existing Decision-support Tools and Pathways for Development. Report for the Comprehensive Assessment of Water Management in Agriculture. International Water Management Institute (in press). 59 pp.

Baran, E. and Jantunen, T. (2004) Stakeholder consultation for Bayesian Decision Support Systems in environmental management. Proceedings of the Regional Conference on Ecological and Environmental Modeling (ECOMOD 2004). Universiti Sains Malaysia, 15-16 September 2004, Penang, Malaysia (in press).

Baran, E., Makin, I. and Baird, I.G. (2003) BayFish: a Model of Environmental Factors Driving Fish Production in the Lower Mekong Basin. Contribution to the Second International Symposium on Large Rivers for Fisheries, 11-14 February 2003, Phnom Penh, Cambodia.

Baran, E., Jantunen, T., Hort, S. and Chheng, P. (2004) Building 'BayFish-Tonle Sap', a Model of the Tonle Sap Fish Resource. ADB/WorldFish Center project 'Technical Assistance for capacity building of IFReDI'; WorldFish Center and Inland Fisheries Research and Development Institute, Department of Fisheries, Phnom Penh, Cambodia, 26 pp.

Beierle, T. (2002) The quality of stakeholder-based decisions. Risk Analysis 22(4), 739-749.

Bertorelle, G., Bruford, M., Chemini, C., Vernesi, C. and Hauffe, H.C. (2004) New, flexible Bayesian approaches to revolutionize conservation genetics. Conservation Biology 18(2), 584.

Borsuk, M.E., Clemen, R.T., Maguire, L.A. and Reckhow, K.H. (2001) Stakeholder Values and Scientific Modeling in the Neuse River Watershed. Group Decision and Negotiation 10, 355-373. $<$ http://www2.ncsu.edu/ncsu/CIL/WRRI/ken\%27s_page.html>

Burke, L., Kura, Y., Kassem, K., Revenga, C., Spalding, M. and McAllister, D. (2000) Pilot Analysis of Global Ecosystem: Coastal Ecosystems. World Resources Institute, Washington, DC.

Cain, J. (2001) Planning Improvements in Natural Resources Management: Guidelines for Using Bayesian Networks to Support the Planning and Management of Development Programmes in the Water Sector and Beyond. Centre for Ecology and Hydrology (CEH), Wallingford, UK, 124 pp.

Cain, J., Jinapala, K., Makin, I., Somaratna, P., Ariyaratna, B. and Perera, L. (2003) Participatory decision support for agricultural management: a case study from Sri Lanka. Agricultural Systems 76, 457-482.

Charniak, E. (1991) Bayesian networks without tears. Artificial Intelligence 12(4), 50-63. <http://wwwpsych.stanford.edu/ jbt/224/Charniak_91.pdf>

Coupé, V.M.H., Peek, N.B., Ottenkamp, J. and Habbema, J.D.F. (1999) Using sensitivity analysis for efficient quantification of a belief network. Artificial Intelligence in Medicine 17, 223-247.

Coupé, V.M.H., van der Gaag, L.C. and Habbema, J.D.F. (2000) Sensitivity analysis: an aid for belief-network quantification. Knowledge Engineering Review 15, 1-18.

De Bruin, B., Fischbeck, P., Stiber, N. and Fischhoff, B. (2002) What number is 'fifty-fifty'? Redistributing excessive 50\% responses in elicitated probabilities. Risk Analysis 22(4), 713-723.

Ellison, A.M. (1996) An introduction to Bayesian inference for ecological research and environmental decision-making. Ecological Applications 6(4), 1036-1046.

Fenton, N. (2004) Biases and Fallacies in Reasoning about Probability. <http://www.dcs.qmw. ac.uk/ norman/BBNs/Biases_and_fallacies_in_reasoning_about_probability__about_this_section.htm>

Gregory, R., McDaniels, T. and Fields, D. (2001) Decision aiding, not dispute resolution: creating insights through structured environmental decisions. Journal of Policy Analysis and Management 20(3), 415-432.

Hahn, M.A., Palmer, R.N., Merrill, M.S. and Lukas, A.B. (2002) Expert system for prioritizing the inspection of sewers: knowledge base formulation and evaluation. Journal of Water Resources Planning and Management March/April 2002, 121-129.

Hoanh, C.T. (1996) Development of a Computerized Aid to Integrated Land Use Planning (CAILUP) at regional level in irrigated areas: a case study for the Quan Lo Phung Hiep region, Mekong Delta, Vietnam. PhD thesis. ITC Publication Number 38, International Institute for Aerospace Survey and Earth Sciences, Enschede, Netherlands.

Hoanh, C.T., Tuong, T.P., Kam, S.P., Phong, N.D., Ngoc, N.V. and Lehmann, E. (2001) Using GIS-linked hydraulic model for managing water quality conflict for shrimp and rice production in the Mekong 
River Delta, Vietnam. In: Ghassemi, F., Post, D., Sivapalan, M. and Vertessy, R. (eds) Proceedings of MODSIM 2001, International Congress on Modelling and Simulation, Vol. 1: Natural Systems (part one), 10-13 December 2001, Canberra, Australia, pp. 221-226.

Hoanh, C.T., Tuong, T.P., Gallop, K.M., Gowing, J.W., Kam, S.P., Khiem, N.T. and Phong, N.D. (2003) Livelihood impacts of water policy changes: evidence from a coastal area of the Mekong River Delta. Water Policy: Official Journal of the World Water Council 5(5/6), 475-488.

Jensen, F.V. (1996) An introduction to Bayesian networks. UCL Press, London, 178 pp.

Kasemir, B., Dahinden, U., Gerger Swartling, Å., Schüle, R., Tabara, D. and Jaeger, C.C. (2000) Citizens' perspectives on climate change and energy use. Global Environmental Change 10, 169-184.

Kuikka, S., Hildén, M., Gislason, H., Hansson, S., Sparholt, H. and Varis, O. (1999) Modeling environmentally driven uncertainties in Baltic cod (Gadus morhua) management by Bayesian influence diagrams. Canadian Journal of Fisheries and Aquatic Sciences 56(4), 629-641.

Lynam, T., Bousquet, F., D'Aquino, P., Barreteau, O., Le Page, C., Chinembiri, F. and Mombeshora, B. (2002) Adapting science to adaptive managers: spidergrams, belief models, and multi-agent systems modeling. Conservation Ecology 5(2), 24. <http://www.consecol.org/vol5/iss2/art24>

Marcot, B.G., Holthausen, R.S., Raphael, M.G., Rowland, M. and Wisdom, M. (2001) Using Bayesian belief networks to evaluate fish and wildlife population viability under land management alternatives from an environmental impact statement. Forest Ecology and Management 153(1-3), $29-42$.

McKendrick, I., Gettinby, G., Gu, Y., Reid, S. and Revie, C. (2000) Using a Bayesian belief network to aid differential diagnosis of tropical bovine diseases. Preventive Veterinary Medicine 47, 141-156.

Ostrom, E. (1990) Governing the Commons. Cambridge University Press, New York.

Ravnborg, H. and Westermann, O. (2002) Understanding interdependencies: stakeholder identification and negotiation for collective natural resource management. Agricultural Systems 73, 41-56.

Reckhow, K.H. (2002) Bayesian approaches in ecological analysis and modeling. In: Canham, C.D., Cole, J.J. and Lauenroth, W.K. (eds) The Role of Models in Ecosystem Science. Princeton University Press. $<$ http:/www2.ncsu.edu/ncsu/CIL/WRRI/ ken's_page.html >

Seidel, M., Breslin, C., Christley, R., Gettinby, G., Reidc, S. and Revie, C. (2003) Comparing diagnoses from expert systems and human experts. Agricultural Systems 76, 527-538.

Soncini-Sessa, R., Castelletti, A. and Weber, E. (2002) Participatory decision making in reservoir planning. IEMSS conference proceedings, Lugano, Switzerland. <http://www.iemss.org/iemss2002/>

Varis, O. (2003) WUP-FIN Policy Model: Finding Ways to Economic Growth, Poverty Reduction and Sustainable Environment. WUP-FIN Socio-economic Studies on Tonle Sap no. 10, MRCS/WUP-FIN, Phnom Penh, Cambodia, 38 pp. <http:/ / www.eia.fi/ wup-fin/>

Varis, O. and Fraboulet-Jussila, S. (2000) Causal Bayesian network approach to integrated watershed planning and management. In: Al-Soufi (ed.) Proceedings of the International Workshop on Hydrologic and Environmental Modelling in Mekong Basin, Phnom Penh, 11-12 September 2000. MRC Publications, Phnom Penh, Cambodia, pp. 204-214.

Varis, O. and Kuikka, S. (1997) Joint use of multiple environmental assessment models by a Bayesian meta-model: the Baltic salmon case. Ecological Modelling 102(2-3), 341-351.

Wilkins, D., Mengshoel, O., Chernyshenko, O., Jones, P., Hayes, C. and Bargar, R. (2002) Collaborative Decision Making and Intelligent Reasoning in Judge Advisor Systems. <http://www.computer.org/proceedings/hicss / 0001/00011/00011061.PDF> 